\title{
On the Cultivation of Intercultural Communicative Competence in the English Viewing-listening-speaking Course
}

\author{
Yueyang Liu \\ Zunyi Medical University, Zunyi, China
}

\begin{abstract}
With the fast pace of globalization, cultivating Intercultural Communicative Competence (ICC) has gradually become a vital goal in English language teaching. However, whether the English Viewing-Listening-Speaking (VLS) course can be used to improve learners' ICC is less researched. This paper tends to adopt skills of discovery, comparison and analysis in Byram's ICC model as methods to explore how students interpret in VLS class and how the interpretation processes improve students' intercultural communicative competence. The design and implementation of teaching activities, combined with the research data including quizzes, students' statement recording and reports, are introduced to illustrate how to improve learners' ICC in VLS course.
\end{abstract}

Index Terms-Intercultural Communicative Competence (ICC), Viewing-Listening-Speaking (VLS), cultivation

\section{INTRODUCTION}

Today, the information age is characterized by cultural diversification, economic globalization, and technological integration. People of different cultural backgrounds have been communicating with each other more and more closely. As a result, the cultivation of intercultural communicative competence (ICC) has attracted more and more attention. We adopt the most widely accepted definition of ICC given by Deardorff (2006) that it is the ability to communicate effectively and appropriately in cross-cultural situations based on personal cross-cultural knowledge, skills and attitudes.

Kong and Luan (2012) defined language as the carrier and expression of culture, meanwhile, culture as the connotation and essence of language. Obviously, helping learners master foreign language skills and acquire ICC are the fundamental goals of foreign language teaching.

Looking at the development of foreign language education in today's world, it is not difficult to find that many countries regard intercultural communication as one of the important purposes of foreign language syllabus. In order to meet the needs of globalization, American students are required to meet the requirements of 5C to improve their foreign language ability. 5C includes Communication, Culture, Connections, Comparisons and Communities (Lu, 2001). Communication and culture in 5C are the core elements of foreign language education (Chen, 2013)

The European Framework (common reference framework for European languages) also proposes that one of the principles of foreign language teaching is to help learners better understand other people's lifestyle, ways of thinking and cultural traditions. Through foreign language learning, it is convenient for them to communicate with each other, eliminate their prejudice and discrimination, so as to realize free flow, mutual understanding and unity (Yang, 2012).

The College English Teaching Guide edited by Wang (2016) clearly pointed out that college English teaching should enhance students' ICC and improve students' comprehensive cultural literacy.

Viewing-listening-speaking (VLS) teaching method integrates viewing, listening and speaking by modern multimedia teaching equipment to improve students' language ability in an all-round way. According to Zhai and Chen (2014), the biggest characteristic of this teaching mode takes full advantage of the videos from the perspective of cultural differences between China and the West. Integrating cultural and liberal education into students' learning and training so as to help students understand world culture, master modern English skills, as well as improve students' ICC and critical thinking ability.

This paper attempts to combine the VLS classroom instruction with the cultivation of students' intercultural communicative competence. The three skills incorporating discovery, comparison and analysis in Byram's ICC model (Byram, 2014), are adopted as methods to explore how students interpret in VLS class and how the interpretation processes improve students' intercultural communicative competence.

\section{Byram’s MODEl OF INTERCULTURAl COMMUNICATION COMPETENCE (ICC)}

The model of ICC proposed by Byram (1997) is widely accepted in intercultural communication studies and foreign language teaching. His model includes five parts: attitude, knowledge, critical awareness, skills of interpreting and 
relating, skills of discovery and interaction.

The first factor, attitude, refers to the student's "curiosity and openness, readiness to suspend belief about other cultures and belief about one's own" (as cited in Elola \& Oskoz, 2008). This factor is about not eager to make positive judgments about one's own culture and negative judgments about other cultures.

The second component, knowledge, refers to familiarity with "social groups and their products and practices in one's own country and in the country of one's interlocutor, and knowledge of the general processes of societal and individual interaction" (Byram, 1997). It relates to two aspects: one is the knowledge about social groups, their products and practice in one's own country as well as that in the target countries or areas and the other is the knowledge about the intercultural interaction process, both of which are crucial and also the prerequisite for a successful intercultural communication.

The third element, critical cultural awareness, refers to "the ability to evaluate critically and on the basis of explicit criteria, perspectives, practices and products in one's own and other cultures and countries" (as cited in Elola \& Oskoz, 2008). In short, the learners with critical cultural awareness are expected to judge the different culture with a more rational, objective and open-minded attitude.

In fact, it is impossible for learners to acquire all the necessary knowledge in various cultural backgrounds. Therefore, learners must possess the skills that enable them to understand unfamiliar knowledge and connect it with familiar knowledge.

Firstly, learners need to have skills of interpreting and relating, which refers to the "ability to interpret a document or event from another culture, to explain it and relate it to the documents from one's own" (Byram, 1997). The detailed explanation is that learners should be equipped with the ability to find misunderstandings and reconcile different opinions in intercultural communication.

Secondly, learners need to have skills of discovery and interaction, which refers to the "ability to acquire new knowledge of a culture and cultural practices and the ability to operate knowledge, attitudes and skills under the constraints of real-time communication and interaction" (Byram, 1997). Even with the lack of real-time communication, learners should be able to explore new cultures and develop the ability to integrate knowledge, attitudes and skills.

In Byram's opinion, knowing another culture is important, but acquiring skills of analysis and interpretation play a more significant role in ICC. Byram (2014) proposed that "discovery", "comparison" and "analysis" should be taken as the main intercultural skills in foreign language teaching. Compared with other models, the above three skills are more conducive to achieve intercultural teaching objectives (Huang, 2013).

\section{The Cultivation of ICC IN VLS Course}

In China, due to limited intercultural communication experiences in classrooms, students are confined themselves to what they have learned in the textbook, and lack of real intercultural communication encounters. Zang (2010) said that language teaching is often separated from the social and cultural environment of the target language, and cultural teaching is usually isolated from language and cultural background, which obviously lead to disconnection between language and cultural education.

However, the author found that the English VLS course has good accessibility and applicability for intercultural education. First of all, curriculum resources are rich and diverse with novel content and practical vocabulary, including excellent English films and television works, celebrity speeches, news resources and documentaries, etc. By utilizing the abundant resources and designing the appropriate tasks, teachers help students get acquainted with the latest developments in the world's politics, economy, and cultures. Through audiovisual activities, students not only exercise their listening and visual observation skills, but also acquire rich cultural knowledge which is conducive to their intercultural communication competence.

Secondly, students are exposed to real, vivid English and are given chances to imitate the correct pronunciation in the video. In this way, they turn English learning into a natural communication activity, which improves students' interest in learning and consolidates their cognitive achievements.

For example, if a teacher wants to describe Thanksgiving Day to students, it is better to let them watch relevant English videos directly at the beginning. The experiment of human memory persistence shows that in the process of learning, the forgetting rate of audio-visual cooperative learning is $18 \%$ after 3 days, which declines slightly compared with the forgetting rate of auditory learning (80\%) during the same time (Feng, 2008). Through effective audio-visual language input, students' learning motivation and interest in learning English are both enhanced.

Scholars at home and abroad have carried out research on the cultivation of ICC in the teaching of viewing-listening-speaking course. Qiu(2005) believed that the VLS course does not adhere to the traditional listening and traditional speaking training mode, but organically combines the two; the course does not carry out language teaching in isolation, but combines language and culture teaching to cultivate students' ICC. Yu and Han (2012) argued that in the VLS classroom, with the assistance of multimedia technology, teachers can effectively guide students to carry out cross-cultural communication with the aid of designing diversified classroom activities and simulating various scenes to create a real language environment. Borghetti (2013) combined cross-culture learning and VLS teaching mode, and put forward to integrate the two in an overall way. Based on the research of Jia(2013), video materials provide students with nonverbal communication information, including gestures, facial expressions, body language, etc., which 
is not available in written reading materials. In fact, in real cross-cultural communication, nonverbal communicative competence sometimes plays a greater role.

VLS course undoubtedly makes up for the defects of reading, grammar and other courses in the cultivation of nonverbal communication ability. Teachers and students make full use of those instructive English video materials that feature in authentic language, human interactions and real physical settings as scenario simulations, thus bridging the gap for lack of real intercultural communication experiences. Education is a kind of cultural behavior so cultivating students' understanding and tolerance of cultural differences can effectively improve their comprehensive quality and ICC at last.

\section{Design And Implementation of TeAching ACtivities in VLS Course}

\section{A. Design of Teaching Activities}

The research was carried out in Zunyi, China. Research participants were non-English major Chinese undergraduate students. They must pass the College English Test Band 4 (CET 4), then they were qualified for this course. CET 4 certificate holders are more likely to have a good facility for English so that teaching effectiveness will be greatly enhanced. Finally, 20 students were chosen to take the VLS course.

A documentary reality show shot by British Broadcasting Corporation (BBC), named "Chinese School: Are Our Children Tough Enough?", is selected as the teaching material. Selecting this material aims to show students the difference between Chinese and English secondary education.

In this project, five outstanding Chinese teachers recruited and selected by BBC went to Bohant middle school in Hampshire, UK, where they wanted to challenge British education system. A one-month Chinese-style education experiment was conducted for 50 British junior three students of Bohant middle school and this special class was called "Chinese school". At the end of the project, they would take the same exam in math, science and Mandarin, together with the students who received British-style education. By comparing their scores, BBC wanted to test which ways of education would lead to better performance. Finally, the average scores of mathematics, science and Mandarin in "Chinese school" were higher than those in British class.

Intercultural context-setting in teaching is mainly based on intercultural texts and audio-visual materials, which can lead to the effective written and oral communication. This BBC documentary was chosen because it was educating and fun. The education discrepancy between Western countries and China can be taken as a good example to develop students' sense of cultural differences and intrigue their critical thinking.

The study takes Byram's ICC skills "discovery", "comparison" and "analysis" as methods to promote students' acquisition of intercultural knowledge, and gradually improve students' open and inclusive intercultural attitude. The teaching process embodies the intercultural teaching principles including speculation, reflection, inquiry, empathy and experience. (Sun, 2016)

\begin{tabular}{|c|c|c|c|c|}
\hline \multicolumn{5}{|c|}{$\begin{array}{r}\text { TEACHING PLAN } \\
\end{array}$} \\
\hline Content & $\begin{array}{l}\text { ICC skills vs. Intercultural } \\
\text { teaching principles }\end{array}$ & $\begin{array}{l}\text { Class } \\
\text { time }\end{array}$ & Class format & $\begin{array}{l}\text { Data } \\
\text { acquisition }\end{array}$ \\
\hline Knowledge & Language points & $60 \mathrm{~min}$ & $\begin{array}{l}\text { Heuristic method of teaching } \\
\text { (teacher ask questions and } \\
\text { students answer the questions) } \\
\text { Task-based teaching }\end{array}$ & Test \\
\hline $\begin{array}{l}\text { Compare the differences between } \\
\text { Chinese education and British } \\
\text { education in the video }\end{array}$ & $\begin{array}{l}\text { ICC skills: discovery, } \\
\text { comparison } \\
\text { Intercultural teaching } \\
\text { principles: inquiry, empathy, } \\
\text { reflection }\end{array}$ & $30 \mathrm{~min}$ & $\begin{array}{l}\text { Group discussion, separate } \\
\text { speech for students }\end{array}$ & Recording \\
\hline $\begin{array}{l}\text { Describe an impressive scene in the } \\
\text { video and compare it with their own } \\
\text { experience in china }\end{array}$ & $\begin{array}{l}\text { ICC skills: discovery, } \\
\text { comparison } \\
\text { Intercultural teaching } \\
\text { principles: inquiry, empathy, } \\
\text { reflection }\end{array}$ & $30 \mathrm{~min}$ & $\begin{array}{l}\text { Group discussion, separate } \\
\text { speech for students }\end{array}$ & Recording \\
\hline Role play & $\begin{array}{l}\text { ICC skill: comparison } \\
\text { Intercultural teaching } \\
\text { principles: empathy, experience }\end{array}$ & $20 \mathrm{~min}$ & Students' performance & $\begin{array}{l}\text { Video } \\
\text { recording }\end{array}$ \\
\hline Reflection & $\begin{array}{l}\text { ICC skill: analysis } \\
\text { Intercultural teaching } \\
\text { principles: speculation }\end{array}$ & $30 \mathrm{~min}$ & Read their reflection reports & $\begin{array}{l}\text { Students' } \\
\text { reflection } \\
\text { report }\end{array}$ \\
\hline
\end{tabular}

Based on teacher-student and student-student interaction, teacher-guided questioning and group discussion, this teaching plan starts from language study to cross-cultural comparison. After familiar with the language points and cultural differences, students take advantage of role play to have a better understanding of the differences. Lastly, analysis and reflection are required to write down in order to show whether their ICC has been improved or not. Furthermore, intercultural goals and language goals are synchronized and promote each other during the whole process. 


\section{Knowledge points}

After watching the documentary, the students were asked to take part in a small test in order to check whether they have understood the contents as well as how much knowledge they have already acquired. There were 20 questions in the test, involving vocabulary and narrative elements of when, where, who, what and why questions. Fifteen students got full marks, three got 17 questions right, and two got 15 questions right. This shows that despite there are some language barriers, students have basically mastered the relevant vocabulary, grammar and general idea of the video clip. The length of sentences and the speed of the conversations appear to be the main obstacles to understanding. Based on the knowledge that students have already grasped, teacher adopted heuristic and task-based teaching method to gradually introduce the important and difficult language points, so that they can have the vocabulary and sentences support in their following study, especially in the oral and written English practice.

For example: (voice-over) After four weeks, the students in the Chinese school will be tested against their British counterparts. Will the long days and strict discipline produce superior students, or will the clash of two cultures create chaos in the classroom?

After watching this short part of video clip, students were required to repeat the voice-over.

However, most of them cannot grasp the whole information. Then teacher played back that part three times and students were required to write down the corresponding sentences. Most of them completed the contents of voice-over just with one word missing---"chaos" that was new to them. Teacher inspired students to think what would happen if two cultures clashed in one classroom, combined with the video clip. After discussion, a student said: "I see a girl really angry and throw her book heavily on the desk, so I think the clash of two cultures maybe lead to mess and disorder." In this way, "chaos" was introduced by students themselves.

Methods like this show that how teacher enlightens students to get the key information.

2. Compare the education differences between Chinese school and Bohant school in the video

At this stage, teacher asked students to answer the following question after watch the video clip.

(1) How is the relationship between teachers and students in the two schools separately?

(2) What is the difference between Chinese and English teaching methods?

(3) What are the different demands by two PE teachers?

Students were encouraged to identifying differences by comparing the Chinese school with its Britain counterpart in the video. These enlightening questions were helpful to arouse students' thinking and guided them to explore the essence of the problem through the phenomenon. After heated discussions, members of each group took turns to express their ideas.

Group A: There is a cultural conflict throughout the documentary: "teachers are the authority" and "students and teachers are equal". In Bohant school, it shows that the relationship between students and teachers is more equal, and there is no obvious distinction between superior and inferior (discovery). In "Chinese school", teachers are generally regarded as unshakable authority, and students unconditionally obey (discovery \&comparison).

Group B: The documentary highlights the conflict between Chinese and English teaching methods. I felt like the British education concept is "herding". You find grass on your own and eat it by yourself. The teacher can help you when you have no choice (discovery). Chinese teaching is "cramming", knowledge is given to you all, you slowly digest it (discovery \&comparison).

Group C: In "Chinese school", the PE teacher in the video has repeatedly stressed the importance of sports performance. Only by getting excellent sports performance can students have the chance to pass the high school entrance examination and go to university. Eva, a British student, said PE was insanely competitive in this Chinese school (discovery). There is no such rule in Britain. In Bohant school, Physical education usually aimed to release pressure, not to prepare for exams (discovery \&comparison).

Based on the discovery and comparison in the video, teachers and students constantly explored the education discrepancy under the different cultural background, with the purpose of deepening students' understanding of each other' s culture and improving students' cross-cultural sensitivity. In the process of students' expression, although they may make some grammatical mistakes or not be fluent in English, their overall language output will not be affected.

3. Describe an impressive scene in the video and compare it with their own experience in china

At this stage, students were stimulated to describe an impressive event or scene in the video and compare it with their own experience in China. Students were also required to discuss in groups and then express their own opinions.

Group A: in the video, we can see that British class is small-sized, with more than 20 students. Children are separated into classes of different abilities. The learning atmosphere is relaxed and the teaching method is student-oriented instead of teacher-centered. A British girl said she did not think comparing oneself to others was a good, healthy lifestyle (discovery). When I was in the third year of junior high school, there were 75 students in a class. Every time we took an exam, our scores would be posted behind the classroom wall, which gave us a lot of pressure. What teachers taught was passively accepted by students. There was no easy learning environment, performance ranking was the most important (comparison).

Group B: one student took the electric kettle to classroom to make tea. After the teapot was confiscated by teacher, he even went to the office and stole it back (discovery). This would definitely not happen in my junior high school, because first of all, from the perspective of class discipline, it was not allowed to take the electric kettle to make tea in 
class. Secondly, the behavior of this kind would be disrespectful to teachers and would also provoke dissatisfaction of students (comparison).

Group C: In the physical education class, two students with excellent academic achievements were disheartened because they failed in the long run test. The British teacher came to comfort the two sad students: "you have tried your best, you did very well" (discovery). In my junior high school, the PE teacher would not comfort you if you failed the physical education examination. He only paid attention to whether you can pass the next exam, that is, he only cared about the results (comparison).

Through the discussion and interaction between teachers and students, students were able to interpret an event from another culture, and relate it to the events from their own. Moreover, they had the ability to choose the appropriate words or vocabularies in the video to introduce their own views, such as "student-oriented", "confiscate", "dishearten", "provoke", "academic performance", etc. In short, students can not only understand each other's culture from different perspectives, but also apply language knowledge into use.

4. Role- play

Role-play is one of the most popular classroom interaction activities for students. It is also helpful for students to change their cultural position through empathy strategy and consciously understand another culture.

At this stage, two students were picked out to act as teachers to give an English demo class separately. The rest acted as junior high students. The two "teachers" would show how to teach words in demo class and five words were selected as an example. Before the performance, the two "teachers" worked together to refine their teaching plans, get familiar with the cultural characteristics of their roles, imitate different teaching styles, and use different language strategies to complete the performance. One adopted Chinese teaching method of inculcating students with knowledge by explaining its meaning and introducing relevant sentences, which was teacher-oriented in the whole process. While another took the British way, that is, teacher designed some games to encourage students to get involved in class. The process was mainly student-oriented. Students needed to give the feedback after the two demo classes.

L said: "I think Chinese education is a good way to deliver knowledge. We wrote the key points according to what teacher said. I like the quiet way of learning."

M held a different view: "Chinese teaching method was so rigid that I was going to sleep."

K said: "The English-style class was very relaxed. Teacher constantly asked questions to motivate us. I also like class discussion, which gave me new ideas from other students."

O disagreed: "Although English-style class was easy and free, I don't like it. I found it boring."

Despite these different attitudes, taking an objective view towards cross-cultural differences and showing respect for foreign cultures are the basis of cultivating ICC. This role-play experience helped students enhance their multi-cultural identity and cross-cultural awareness.

5. Analysis and reflection

By comparing and analyzing the discrepancy between Chinese and English education, students learned to reflect on their positions in intercultural communication, which facilitated an inclusive and open cross-cultural attitude. Students were guided to think about the deep reasons for the differences and also required to write down their reflection reports.

A's report: the large number of Chinese populations means people have to face the fierce social competition and receive unequal education resources. To maintain the education fairness, I think the Chinese education system is a good way.

B' report: It is well-known that Chinese education is exam-oriented. When we look back to our school life under the Chinese education, many of us feel disappointed and helpless. But when the knowledge we learned during that time coming to mind, no one can deny the advantage of it."

Data of this kind shows that students hold a positive attitude towards Chinese education. They can clearly explain the rationalization of Chinese education system and express its benefits from their own perspectives. Some students go into details of the documentary to interpret the culture reflected in the video clip.

Student C: Chinese education is a quick way to learn knowledge. In the process of the experiment, we found that all the discussions were omitted, leaving only the final results, which can never be wrong in the notebook. When British children get the results through various experiments, Chinese children have recited ten formulas. This is the difference. One attaches importance to the process, and the other attaches importance to the result. It is difficult to say which is good or which is bad.

Student D's report: Whether it is Chinese education or Western education, as long as it is the best system for student's development and progress, it is a good system.

The four steps that include the explanation of knowledge points, the analysis and comparison of Chinese and English education modes, as well as the role-play and reflection, provide students with chances to experience different cultures in a multi-edged mirror, which undoubtedly enhance their learning enthusiasm and class interaction. By comparing these different interpretations of the same event, students with the critical thinking ability can easily jump out of their own conventional thinking mode and their understanding of the two cultures could also be deepened.

\section{Feedback}

In order to understand the students' feelings about the course, a questionnaire survey was conducted on the students. A total of 20 valid questionnaires were collected. The questionnaire listed ten questions, mainly about how well the 
teaching effect was and whether students' ICC has been cultivated or not. Students also made free to comment on this teaching case.

In the students' feedback, $90 \%$ of the students held a positive attitude towards the teaching effect, among them, $20 \%$ of the students thought the case was very enlightening while 35\% of the students used "interesting" to describe their feelings of the case. $83.3 \%$ of the students thought this teaching case provided them with a very different perspective on cultural phenomena and $95 \%$ of these respondents insisted that an inclusive and open cross-cultural attitude was significant in intercultural communication. In addition, students' comments also included the following words: "informative", "helpful", "with strong visual impact", etc. A student commented that in the future, when communicating with foreign teachers or friends, we should think more about it, learn to respect their culture, and introduce our traditional culture to them. Wen also (2014) pointed out that in English teaching, teachers should emphasize cultural consciousness by cultivating students' ability to spread Chinese culture and tell Chinese stories in English rather than pay only attention to learn other culture.

This case study shows that by interactive communication and participation teaching mode, students learn to reflect and analyze different cultures, which enhances their willingness to intercultural communication as well as promotes their intercultural communicative competence. Students with conceptual understanding of culture are more likely to accept the range of values and behaviors among different cultural groups (Cotton, 1996). In turn, the implementation of cross-cultural tasks also promotes their learning and use of language. The task implementation, including role-play, classroom discussion, story continuation and so on, also effectively trains students' cross-cultural skills--- discovery, comparison and analysis. The difficulty of tasks depends on the students' learning ability.

\section{CONClusion AND ReCOMmEndations FOR LANGUAGE TEACHERS}

Byram's cross-cultural skills are adopted to guide students to compare their own culture and other cultures, so as to carry out meaningful cross-cultural learning. But the selection of teaching material should depend on the teaching objectives of a specific module. Teachers should be selective with scenes with pornography, swear words, or violence that may be offensive to students with strong religious belief or moral values. Appropriate task design and theoretical foundation are also critical. Byram's ICC model and skills are encouraged to be implemented in the task design with the aim of improving students' ICC awareness.

The case study shows that documentaries, news clips and foreign films, especially those with multi-cultural elements, play an important role in the cultivation of students ICC. Students show great enthusiasm for cross-cultural comparison in VSL courses and they also like to incorporate video watching into their class because of its diversity of content and form, its authenticity of language and scenes, its vivid reflection of social culture, values and ways of thinking. Since intercultural communication tasks involve in intercultural social relations and intercultural communicative behaviors, language teachers should take full advantage of various activities such as role play, simulation, cultural comparison, drama to achieve their teaching goals.

By selecting appropriate video material, asking appropriate prompt questions, assigning cultural context tasks as well as designing related classroom activities, teachers can facilitate the development of the students' intercultural communicative competence.

VSL course is of great significance to the cultivation of intercultural talents. In this paper, the cross-cultural training mode is integrated into the VSL English course, which provides a practical way for the development of students' ICC. Although cross-cultural teaching is a complex and time-consuming work from design to implementation, the teaching methods eventually not only help students better acquire knowledge and improve their professional ability, but also develop and improve their understanding of themselves and the world. How to integrate the cross-cultural training mode into foreign language classroom teaching effectively is worthy of further exploration by foreign language teachers through a lot of classroom practice and research.

\section{REFERENCES}

[1] Byram, M. (2014). Teaching and assessing intercultural communicative competence. Shang Hai: Shanghai Foreign Language Education Press.

[2] Byram, M. (1997). Teaching and assessing intercultural communication competence. New York: Multilingual Matters.

[3] Borghetti, C. (2013). Integrating intercultural and communicative objectives in the foreign language class: A proposal for the integration of two models. The Language Learning Journal, 3, 254 -267.

[4] Chen Baiying. (2013). Exploration of intercultural communication course based on cultural literacy cultivation. Journal of Ningbo Institute of Education, 15(04), 69-72.

[5] Cotton, C. (1996). A bold experiment in teaching values. Educational Leadership, 53(8), 54-58.

[6] Deardorff, D. (2006). Identifications and assessment of intercultural competence as a student outcome of internationalization. Journal of Studies in International Education, 3, 241-253.

[7] Feng Zhijing. (2008). Film and the cultivation of intercultural communicative competence in English viewing, listening and speaking teaching. Film Review, 10, 62-63.

[8] Huang Wenhong. (2013). A theoretical model of intercultural communicative competence: a comparison between China and the West. Journal of Xi'an International Studies University, 21(04),37-40.

[9] Idoia Elora \& Ana Oskoz. (2008). Blogging: Fostering intercultural competence development in foreign language and study 
abroad contexts. Foreign Language Annals, 41(3), 454-477.

[10] Jia Ying. (2013). The cultivation of intercultural communicative competence in English audio visual course. Chinese Journal (Foreign Language Education and Teaching), 12, 103-104.

[11] Kong Deliang \&Luan shuwen. (2012). On the construction of intercultural teaching mode of college English. Foreign Language World, 2, 17-18.

[12] Lu Xiaoyong. (2001). American "5C" foreign language education in the 21st century. Foreign Language Circles, 5, $22-27$.

[13] Qiu Li. (2005). On the cultivation of intercultural communicative competence in English audio-visual-oral teaching. Journal of Anhui Agricultural University (Social Science Edition), 14(1), 141-144.

[14] Sun Youzhong. (2016). Foreign language education and intercultural competence training. Chinese Foreign Languages, 3 , $16-22$.

[15] Wang Shouren. (2016). Key points of college English teaching guide. Foreign Language Circles, 3, 2-10.

[16] Wen Qiufang. (2014). The dispute between general English and English for specific purposes in college English teaching: Problems and countermeasures. Foreign Languages and Foreign Language Teaching, 1, 1-8.

[17] Yang Qiong. (2012). The new ideas of foreign language teaching proposed by the European common reference framework. Northern Literature, 4, 206-207.

[18] Yu Shulin \&Han jiying. (2012). An exploratory study of college foreign language classroom environment. Foreign Language Circles, 01, 27-34.

[19] Zhai Xiangjun \&Chen Yongjie. (2011). Audi- visual-oral course of college practical English in the 21st century. Shang Hai: Fudan University Press.

[20] Zang Qing. (2010). Problems and suggestions of culture introduction in college English teaching. Journal of Tonghua Normal College. 31 (5), 24-26.

Yueyang Liu was born in Zunyi, Guizhou Province, China in 1985. She majored in International Trade and Economy, Beijing International Studies University from 2004-2008. She got master degree in English Translation, Guizhou University in 2015. She has taught college English for non-English majors in Zunyi Medical University since 2015. Her research areas of interest include English translation and Second Language Acquisition. 